\title{
How to design compact mass transfer packing for maximum efficiency
}

\author{
H. Goshayshi \\ Department of Mechanical Engineering, \\ Azad University of Mashhad (IAUM), Iran
}

\begin{abstract}
The effect of form with corrugated packing on mass transfer and pressure drop characteristics in atmospheric cooling towers has been studied experimentally. The results showed that the mass transfer coefficient decreased with increase in packing pitch and increase in the ratio of rib pitch to rib height. Friction factors were expressed by a dimensional equation which included pitch and distance between the packings, for both smooth and rough surface. From these results, the relationship between packing mass transfer coefficient and pressure drop was deduced. The correlations were verified with additional experimental data taken with $1.1<\mathrm{P} / \mathrm{D}<1.70$ and $1 \leq \mathrm{p} / \mathrm{e} \leq 5$. This provides a useful semi-experimental relation, in the area generally lacking in design and performance data.

Keywords: packings, mass transfer and pressure drops.
\end{abstract}

\section{Introduction}

In general, the design of an efficient, compact mass transfer pack for gas/liquid applications is based on the optimisation of the passage diameter and passage length. Also from a number of recent studies it is apparent that the choice of material plays a major role in packing design, the ideal material being highly formable in order to provide a high specific surface area, Egberongbe [3]. Heat and mass transfer between a falling liquid film along a vertical wall and upward flowing air contacting directly with the film is an important and interesting phenomenon in industrial apparatus such as cooling towers. While $96 \%$ of the cooling towers use PVC packing with smooth and cross ribbing, no data on the flow of liquid over a flat vertical wall with cross ribbing have been published. Only some of the features of their operation in contact heat exchangers have 
been investigated by $[1,2,4-6]$. Major aspects that remain to be studied include: the geometry and layout of the main corrugation with and without the cross ribbings, the pattern of flow of the liquid film and interaction between phases. In this paper the mass transfer and pressure drop characteristics of many types of corrugated packing, including smooth and rough surface corrugated packings, are investigated, and the relationship between packing mass transfer coefficients and pressure drops are discussed. Mass transfer performance of rough corrugated packing is increased by 1.5 to 2.5 times the smooth packing values, but the pressure drop of packings also increases with the increase in heat transfer performance.

\section{Experimental apparatus and procedure}

The experimental apparatus for the heat transfer experiments, consisted of a counterflow forced draft cooling tower, as shown in fig. 1. Water stored in a tank at the base was pumped into the spray nozzles. The supply water velocity was regulated by a valve. The cross sectional test area was $A=0.15 \times 0.15 \mathrm{~m}$. Inlet and outlet air and water temperatures were measured by mercury in glass thermometers with a range of $0-50^{\circ} \mathrm{C}$ and an accuracy of $0.2 \mathrm{~K}$. Packing pressure drop was measured by an APM 2000 (0 to $2000 \mathrm{~Pa}$ ) micromanometer with an accuracy of $\pm 1 \%$ FSD (i.e. maximum of $1.2 \mathrm{~Pa}$ error in our measurements). Measurements of mass transfer and pressure drop were carried out in the steady state. The mass transfer coefficients and pressure drops were measured for a range of $\mathrm{L} / \mathrm{A}\left(L^{\prime}\right)$ from 0.45 to $2.22 \mathrm{~kg} / \mathrm{m}^{2} \mathrm{~s}$ and $\mathrm{G} / \mathrm{A}\left(G^{\prime}\right) 0.20$ to $1.50 \mathrm{~kg} / \mathrm{m}^{2} \mathrm{~s}$. A series of perimeter deflector plates was installed around the inner perimeter of the column, made in the laboratory of clear Poly Carbonate plastic to allow observation of the water flow. These deflector plates removed the water film from the wall of the tower's column and redistributed the water in the packing zone. As a result of deflection, most of the water was transferred to the packing surface from the outer wall, forming descending thin films, while air was blown vertically upward, counter current to the water by a fan at the base. The packings tested were of two types, smooth and ribbed, both of PVC. The smooth packing had horizontal corrugations and the ribbed had horizontal corrugations with ribbing set at an angle to the main corrugations. The cross ribs were separated by distance $\mathrm{p}$, ranging from $2 \mathrm{~mm}$ to $10 \mathrm{~mm}$, for the six sample packings, and the height e of the ribs ranged from $1 \mathrm{~mm}$ to $3 \mathrm{~mm}$. The main corrugation pitch, $\mathrm{P}$, ranged from $30 \mathrm{~mm}$ to $70 \mathrm{~mm}$. The thickness of packing was negligible. The forms of corrugated packings used in the experiments are listed in table 1, and typical shapes are shown in figs. 2, 3 and 4 . The column packed height, $Z$, was $160 \mathrm{~cm}$ and the water level in the sump was about $1.2 \mathrm{~m}$ below the top of the packing. Water inlet and outlet temperatures were $37^{\circ} \mathrm{C}$ and $27^{\circ} \mathrm{C}$ respectively. 
Table 1: $\quad$ Shapes of corrugated packing used.

\begin{tabular}{||c|l|c|c|c||}
\hline $\begin{array}{c}\text { Test } \\
\text { Grou } \\
\mathrm{p}\end{array}$ & $\begin{array}{l}\text { Type } \\
\text { of } \\
\text { corrugation }\end{array}$ & $\mathrm{P} / \mathrm{D}$ & $\mathrm{p} / \mathrm{e}$ & $\begin{array}{c}\theta \\
(\mathrm{deg})\end{array}$ \\
\hline $\mathrm{C} 1$ & sinusoidal & 1.40 & 1 & 45 \\
$\mathrm{C} 2$ & sinusoidal & 1.65 & 3 & 0 \\
C3 & triangular & 1.13 & - & - \\
C4 & triangular & 1.43 & 4 & 0 \\
C5 & hexagonal & 1.32 & 5 & 0 \\
C6 & sinusoidal & 1.50 & 4 & 45 \\
C7 & triangular & 1.50 & 5 & 0 \\
\hline
\end{tabular}

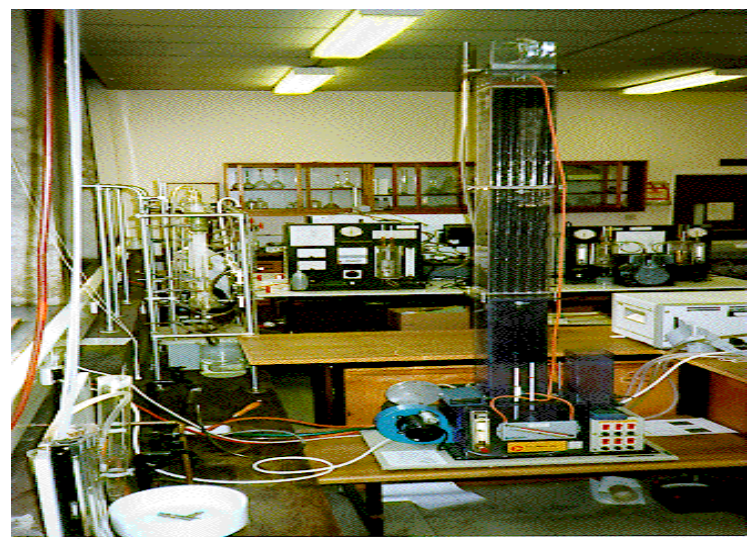

Figure 1: $\quad$ Outside view of forced draft cooling tower in laboratory.

\section{Experimental results}

\subsection{Heat transfer characteristics}

Cooling tower packings typically have quite complex surface geometries, for which the mass transfer co-efficient, $\mathrm{k}$, cannot be analytically predicted. Because manufacturers treat such data as proprietary, the $\mathrm{k}$ relation should be derived from test data, specific to the packing geometry.

Fig. 5 shows values of measured mass transfer coefficient $k$, plotted against the ratio of water flow rate to air flow rate $(\mathrm{L} / \mathrm{G})$ for existing packings. The values of $\mathrm{k}$ for corrugated packing were 1.5 to 2.5 times higher than comparable smooth packing $\mathrm{k}$ values when the water to air ratio was 1.0 . The $\mathrm{k}$ values for rough and smooth corrugated packings decreased with the increase in pitch, and had a maximum value when $\mathrm{P} / \mathrm{D}=1.5$ and the ratio of distance between repeated ribs to height of rib was 4 , and the angle, $\theta, 45^{\circ}$. (Packing C6). 


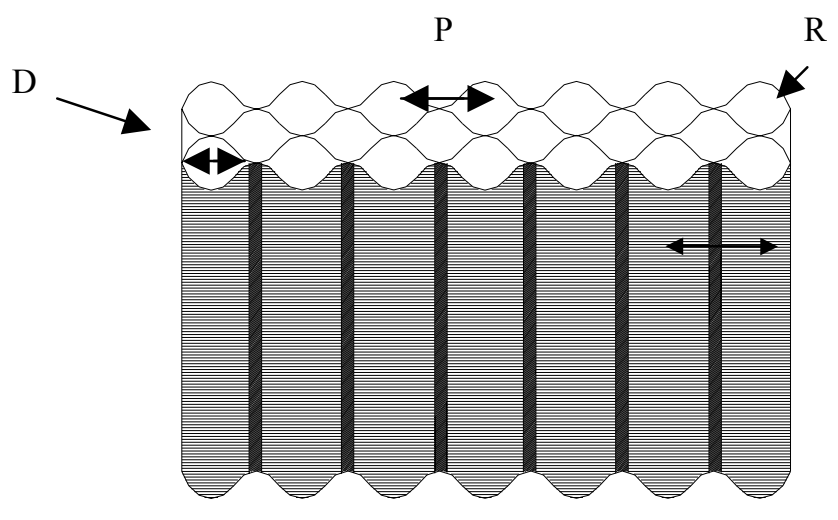

Figure 2: Typical shape of smooth corrugated packing used in our experiment.

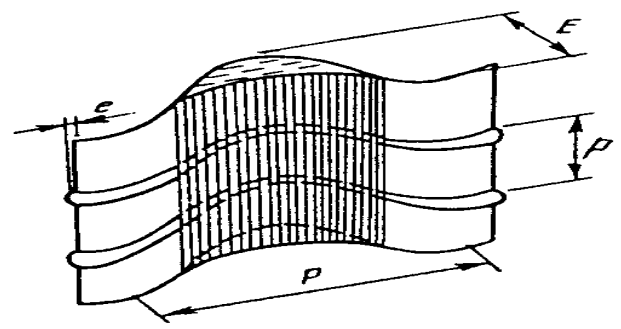

Figure 3: $\quad$ Single cross ribbed sheet.

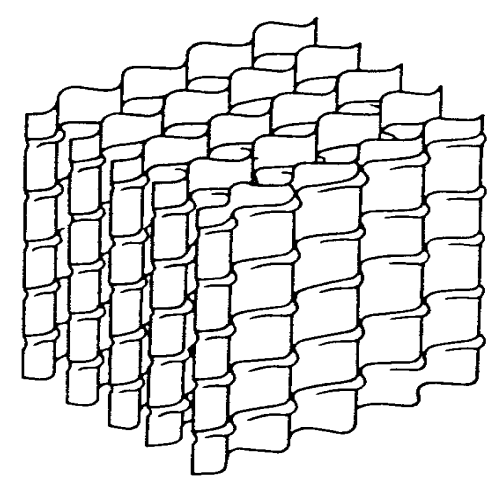

Figure 4: Typical shape of rough corrugated packing used in our experiment. 


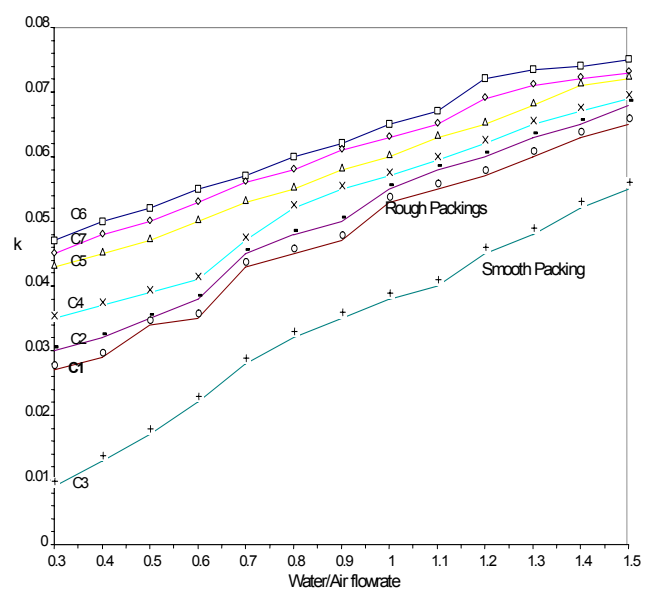

Figure 5: Heat transfer characteristic of packing with different spacing and surface roughness.

As it can be seen from ,fig. 5 , $\mathrm{k}$ increases with

(i) decrease of the spacing between the sheets, all other parameters being constant.

(ii) increase in the value of $L^{\prime}$, for $G^{\prime}=$ constant.

(iii) increase in the ratio of the pitch of the corrugation to the spacing. P/D should be of the order of 1.5 and p/e should be of the order 5 to have maximum heat transfer.

(iv) decrease of the ratio of distance between repeated ribs and height of the rib.

(v) decrease in $\theta$.

It can see that mass transfer increases with the decrease in spacing, but higher mass transfer in packing C6 compared with C7 and C5 is likely to be due mainly to the difference in the effect of the packing wall roughness[factors (iv and v) above]. The resultant correlation $\mathrm{k}$ of the Nos 1 to 7 was determined from these experiments with the most susceptible to error of $\pm 4 \%$ by;

$$
\mathrm{k}=\mathrm{c}_{1}\left(L^{\prime}\right)^{0.45}\left(G^{\prime}\right)^{0.6}
$$

$c_{1}$ is an experimental constant. The constant for type No. 3, (smooth surface), is 1.20 while for type Nos $1,2,4-7$ the constant is $1.75,1.83,190,1.98,2.20,2.10$ respectively. Using the smooth sample, No 3 as reference, the relative increases due to ribbing were, for No. $1=1.45$, for No. $2=1.52$, for No. $4=1.58$, for No. $5=1.65$, for No. $6=1.83$, and for No. $7=1.75$ respectively. 


\subsection{Pressure drop characteristics}

Another aspect of the investigation of the performance of packings concerned pressure drop characteristics.

As it can be seen from fig. $6 \Delta \mathrm{P}$ increases with

(i) decrease in spacing between the sheets when all the other parameters being constant.

(ii) increase in $L^{\prime}$, for $G^{\prime}=$ constant.

(iii) increase of the ratio of distance between repeated ribs and height of rib.

(iv) decrease in $\theta$.

The resultant of pressure drop for the packing No. 1 to No.7 is expressed with the most susceptible to error of $\pm 3 \%$ by;

$$
\Delta \mathrm{P}=\mathrm{c}_{2}\left(L^{\prime}\right)^{0.35}\left(G^{\prime}\right)^{0.55}
$$

$\mathrm{c}_{2}$ is an experimental constant. The constant for type No. 3 having a smooth surface is 17.7 while those for types Nos. 1, 2, 4-7, are 20.5, 22.6, 25.6, 27.8, $30.7,32.5,35.2$, respectively. The result in fig. 6 shows that the pressure drop of packing $\mathrm{C} 7$ is about $70 \%$ higher than that of $\mathrm{C} 1$. This difference appears to be caused by difference in the height of the corrugations and the different surface created by the ribs.

The only exception is for $\mathrm{C} 6$ of the present investigation (spacing of $20 \mathrm{~mm}$ ). The pressure drop is lower by about $15 \%$ than the pressure drop for the $\mathrm{C} 7$ (spacing of $20 \mathrm{~mm}$ ). This difference can be attributed to the difference of the turbulent flow condition caused by the wall roughness of the packing created by the lower distance between the plates.

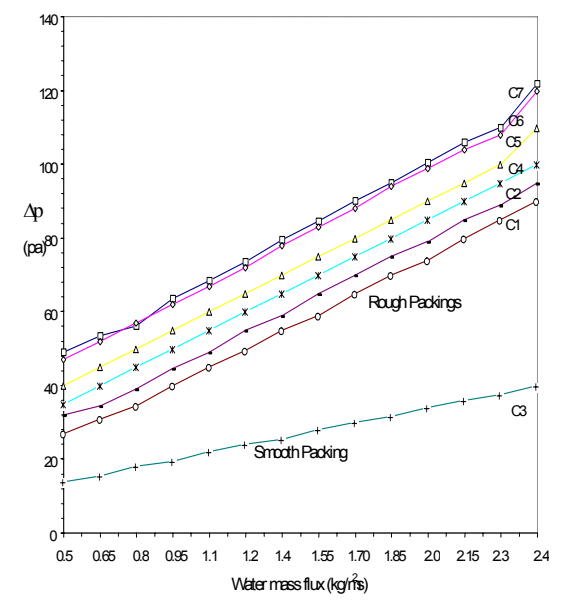

Figure 6: Pressure drop characteristic with different spacing and surface roughness. 


\section{Discussion}

In relatively narrow, corrugated packings flow separation takes place near the ridge of every corrugation, and flow re-attachment takes place upstream of the next ridge in the flow directions. The troughs of the corrugations are partly filled with re-circulating fluid. It was found that a packing of particular interest was the packing $\mathrm{C} 6$, which has a vertical main corrugation with the cross ribbing making an angle of $45^{\circ}$. Flow separation enhances the turbulence of the flow (compared with corresponding flow between smooth, straight wall) and thereby increases mass transfer rate and pressure drop, (e.g. Packing C6). A packing with high turbulence in combination with a relatively low fluid velocity is more economic than a fairly smooth and straight packing in combination with a high fluid velocity. The results showed that mass transfer performance of the corrugated packing is increased by up to 1.5 to 2.5 times compared to the smooth packing, $\mathrm{C} 3$. In order to have the maximum mass transfer, the ratio of the pitch to spacing of the corrugation, $\mathrm{P} / \mathrm{D}$ should be of the order of 1.36 to 1.50 .

In this study packing mass transfer coefficients, $\mathrm{k}$, of corrugated packings were expressed by Eqn. (1). It was found that, for the effect of pitch on the Nusselt number $(\mathrm{Nu})$, the value $\mathrm{C}$ was approximated to by $(\mathrm{P} / \mathrm{D})^{-0.15}$.

\section{Conclusions}

Experiments were conducted to investigate the effect of the spacing and surface roughness on the mass transfer and pressure drop in PVC packing for which no comprehensive investigations had previously been reported. The experiments were carried out for comparative types of packing in a counterflow cooling tower. From the experimental results and discussion on the performance characteristic of seven vertical parallel packings arrangement in forced draft counterflow cooling tower the following conclusions may be drawn;

(1) Overall mass transfer coefficients and pressure drops of ribbed corrugated packings increase considerably compared with smooth packing and are affected by spacing of the packing and the distance between the ribs.

(2) It was found that the shape and configuration of the roughness projections are as important as the height of those projections in determining their effect on Fanning friction factor and mass transfer coefficient. It was found that a packing of particular interest was the packing $\mathrm{C6}$, which had maximum mass transfer value at $\mathrm{P} / \mathrm{D}=1.5$ and the ratio 4 for the ratio of distance between repeated ribs to height of rib with the cross ribbing making an angle of $45^{\circ}$.

(3) Packing mass transfer coefficients vary in proportion to $(\mathrm{P} / \mathrm{D})^{-0.15}$ and $\mathrm{C}$ the value decreased with increase in $\mathrm{P} / \mathrm{D}$.

(4) Friction factors of corrugated packings vary in proportion to (P/D $)^{-0.94}$ and $(\mathrm{p} / \mathrm{e})^{-1.52}$.

(5) Mass transfer coefficients of corrugated packing vary in proportion to the 0.41 power of pressure drop per unit height. This value of 0.41 is smaller than smooth packing value 0.46 . 


\section{Symbols}

$\begin{array}{lll}\mathrm{A} & \text { Surface area per unit volume } & \mathrm{m} \\ \mathrm{D} & \text { Distance between the tower packing } & \mathrm{mm} \\ \mathrm{e} & \text { Height of roughness } & \mathrm{mm} \\ \mathrm{G} & \text { Flow rate (air) } & \mathrm{kg} / \mathrm{s} \\ G^{\prime} & \text { Mass flux (air) } & \mathrm{kg} / \mathrm{m}^{2} \mathrm{~s} \\ \mathrm{E} & \text { Height of corrugation } & \mathrm{mm} \\ \mathrm{L} & \text { Flow rate (water) } & \mathrm{kg} / \mathrm{s} \\ L^{\prime} & \text { Mass flux (water) } & \mathrm{kg} / \mathrm{m}^{2} \mathrm{~s} \\ \mathrm{k} & \text { Mass transfer coefficient } & \mathrm{kg} / \mathrm{m}^{2} \mathrm{~s} \\ \mathrm{p} & \text { Distance between repeated ribs } & \mathrm{mm} \\ \mathrm{P} & \text { Pitch of packing } & \mathrm{mm} \\ \mathrm{Pr} & \text { Prandtl Number } & \mathrm{dimensionless} \\ \mathrm{Z} & \text { Packed height } & \mathrm{m} \\ \mathrm{Re} & 2 L_{\mathrm{w}}^{\prime} \text { D/ } \mu_{\mathrm{w}} & \mathrm{dimensionless} \\ \rho_{\mathrm{a}} & \text { Air density } & \mathrm{kg} / \mathrm{m}^{3} \\ \mathrm{u}_{\mathrm{a}} & \text { Air velocity inside the packing } & \mathrm{m} / \mathrm{s} \\ \mathrm{u}_{\mathrm{w}} & \text { Water velocity inside the packing } & \mathrm{m} / \mathrm{s} \\ \theta & \text { Angle of cross ribbing with the horizontal } & \circ\end{array}$

\section{References}

[1] Bernier, M. A., Thermal performance of cooling towers, ASHRAE Journal, 4, pp. $2631,1995$.

[2] Bukowski. J., Taking the heat off industrial processes, Consulting Specifying Engineer, 10, pp. 32 38, 1995.

[3] Egberongbe, S. A., How to design compact mass transfer packing for maximum efficiency, Process Engineering, 9, pp 5 11, 1990.

[4] Kranc, S. C., Performance of counterflow cooling towers with structured packings and maldistributed water flow, Numerical Heat Transfer, 23, pp 15 23, 1993.

[5] Marselle, A., Progress in Heat and Mass Transfer, ASHRAE Journal, 9, pp 56 62, 1991.

[6] Nabhan, B. W \& Anabtawi, M., An investigation into a falling film type cooling tower, International Journal of Refrigeration, 18(8), pp 19 25, 1994. 